\title{
Ekonomik ve İşlevsel Bir Robotik Eğitim Setinin Geliștirilmesi: ARUbot ${ }^{*}$
}

\author{
Arif Cem TOPUZ \\ arifcemtopuz@ardahan.edu.tr \\ Hasan Hüseyin ÇOBAN \\ huseyincoban@ardahan.edu.tr \\ Samet ARSLAN \\ Ankara Keçiören Toygar Börekçi Ortaokulu, \\ samet1454@gmail.com \\ Sedat TUFANÇLI \\ Kocaali Halk Eğitim Merkezi \\ sedat.tufancli@gmail.com
}

Ardahan Üniversitesi, Mühendislik Fakültesi, Bilgisayar Mühendisliği Bölümü,

Ardahan Üniversitesi, Mühendislik Fakültesi, Elektrik Elektronik Mühendisliği Bölümü,

\begin{tabular}{|c|c|}
\hline Makale Bilgileri & ÖZ \\
\hline $\begin{array}{l}\text { Anahtar Kelimeler: } \\
\text { Robotik Kitler, } \\
\text { Robotik Eğitimi, } \\
\text { Robot Kodlama, } \\
\text { STEAM. }\end{array}$ & $\begin{array}{l}\text { Bu çalışmanın amacı; elektronik ve robotik kodlama eğitiminde kullanılabilecek, } \\
\text { programlanması basit, kısa devre korumalı, yazarak veya blok tabanlı } \\
\text { kodlanabilen, modül bağlantılarının kolayca görülebildiği, lisanslama ve telif hakkı } \\
\text { sorunu bulunmayan, düşük maliyetli, kamu kaynaklarının dışa aktarımını } \\
\text { azaltabilecek nitelikte, üniversitenin kendi robotik eğitim setini geliştirmektir. Bu } \\
\text { amaçla yapılan geliştirme çalışmasında robotun nasıl tasarlanabileceği, maliyetinin } \\
\text { ne kadar olacağı ve hangi uygulamaların yapılabileceğine odaklanılmıştır. } \\
\text { Sistem/Yazılım Proje Yönetim Modellerinden Şelale Modelinin baz alındığı bu } \\
\text { çalışmada Ardunio isimli geliştirme kartı kullanılmışve Arduino destekli toplam } 11 \\
\text { modülden oluşan bir eğitim robotu prototipi üretilmiştir. ARUbot ismi verilen bu } \\
\text { robot ile üzerindeki modüllerin çeşitli kombinasyonlarla kullanılması neticesinde } \\
\text { toplam } 2047 \text { farklı kullanım elde edilebilmektedir. Ayrıca ARUbot; çizgi } \\
\text { izleyebilme, engelden kaçabilme, sıcaklık ve nemi ölçebilme, ışı durumunu } \\
\text { ölçebilme, bluetooth ile kontrol edilebilme, ekranına yazı yazabilme gibi daha } \\
\text { birçok işlevi bir arada yerine getirebilmektedir. Üstelik böyle bir robotun } \\
\text { üniversite tarafından üretilmesi sayesinde, maliyetinin emsallerinden yaklaşı } 8 \\
\text { kat daha düşük olduğu anlaşılmıştır. Ülkemizin politika yapıcıları ve eğitim } \\
\text { kurumları yöneticileri tarafından bu çalışma kapsamında ortaya koyulan } \\
\text { bulguların dikkate alınması sayesinde, yurtdısı menşeili robotik kodlama eğitim } \\
\text { setleriyle kamu kaynaklarının yurtdışına akmasının azaltılabileceği söylenebilir. }\end{array}$ \\
\hline
\end{tabular}

\footnotetext{
* Bu çalışma, Ardahan Üniversitesi Bilimsel Araștırma Projeleri Koordinatörlüğü tarafından desteklenen 2018-001 proje numaralı ve "Ardahan Üniversitesi Elektronik ve Kodlama Eğitimi Robotunun Geliştirilmesi: ARUbot" başlıklı proje kapsamında hazırlanmıştır.
} 


\section{Development of an Economic and Functional Robotics Training Set: ARUbot}

\begin{tabular}{|c|c|}
\hline Article Info & ABSTRACT \\
\hline Article History & The aim of this study is to develop the university's own robotics training set, \\
\hline Received: 27.08.2019 & which; can be used in electronic and robotic coding education, is easy to \\
\hline Accepted: 15.11 .2019 & $\begin{array}{l}\text { program, is circuit protected, can be coded by written or block-based, is easy to } \\
\text { see module connections, has no licensing and copyright problems, can reduce }\end{array}$ \\
\hline Published: 20.12 .2019 & $\begin{array}{l}\text { the usage and also outflow of public resources. In this development study, we } \\
\text { focused on; how the robot can design, how much it will cost and what } \\
\text { applications can be done. In this study, based on the Waterfall Model, which is } \\
\text { one of the System / Software Project Management Models, a development card } \\
\text { named Ardunio was used and an educational robot prototype consisting of } 11 \\
\text { modules was produced with Arduino support. With this robot called ARUbot, a } \\
\text { totally of } 2047 \text { different usage can be achieved by using the modules on it with } \\
\text { various combinations. Also, ARUbot can perform many other functions such as } \\
\text { line tracking, avoiding obstacles, measuring temperature and humidity, } \\
\text { measuring light status, controlling with bluetooth, writing text on the screen. }\end{array}$ \\
\hline Keywords: & Moreover, thanks to the fact that such a robot is manufactured by the \\
\hline Robotics Kits, & university, it has been found that its cost is about 8 times lower than its peers. \\
\hline Robotics Education, & $\begin{array}{l}\text { Considering the findings put forward by the policy makers and educational } \\
\text { institutions of Turkey within the scope of this study it can be said that the flow }\end{array}$ \\
\hline Robotics Coding, & of public resources abroad can be reduced with robotic coding training sets \\
\hline STEAM. & \\
\hline
\end{tabular}

\section{GİRIŞ}

Öğretim teknolojileri, günümüzde eğitim alanına getirdiği yeniliklerle dikkat çekmeye devam etmektedir. Bu noktada, özellikle STEM veya STEAM, çok sık duyulan kavramlar haline gelmiştir. Science (Fen), Technology (Teknoloji), Engineering (Mühendislik) ve Mathematics (Matematik) kelimelerini temsilen oluşturulan STEM (FeTeMM); Art (Sanat) kelimesinin eklenmesiyle artık STEAM olarak anılmaya başlamıștır (Colucci-Gray, Burnard, Gray ve Cooke, 2019). STEAM öğrencilerin bilişsel, duyuşsal ve psikomotor becerilerini geliştirmede oldukça önemli katkılar sunabilen bir araç/yöntem olarak kullanılmaktadır. Bu değerli katkı nedeniyle, birçok ülkede öğrencilerin becerilerini STEM ile geliştirmeye odaklanılan araştırmaların (An, Yang, Wang, J., ve Du, 2019; Suter ve Camilli, 2019) yapıldığı görülmektedir. Gelişmiş ülkelerde olduğu gibi Ülkemizde de bu alana yönelik yatırımların yapılması elzemdir (Akgündüz vd., 2015).

Ülkemizde üreten ve üretimi yerli kaynaklarla yapan kurumlar, şirketler ve bireyler yetiştirilmesine yönelik yoğun bir çabanın sarf edildiği günümüzde; eğitim alanında da yatırımların yerlileştirilmesi göz ardı edilmemesi gereken hususlardan birisi kabul edilebilir. $\mathrm{Bu}$ noktada STEAM ile son günlerde popülerliği artan özellikle robotik kodlama eğitimine yönelik adımların planlanarak atılması önem arz etmektedir. Çünkü, kamu kurumlarımız tarafından robotik kodlama eğitimine yönelik birçok mal veya hizmet alımı yapıldığı Kamu İhale Kurumu'nun web sitesinden (https://ekap.kik.gov.tr) takip edilebilmektedir. İlgili web sitesinden "robot eğitim" anahtar kelimesiyle 10/10/2019 tarihinde yapılan tarama neticesinde son 3 yılda (20172019) 10 adet mal alımı ve 2 adet hizmet alımı yapıldığı anlaşılmaktadır. Ancak, bu satın almaların içerikleri incelendiğinde, kamu kaynaklarının yabancı menşeili robotik kodlama eğitim setleri aracılığıyla yurtdışına aktı̆̆ı hemen göze çarpmaktadır.

Yurt dışından ithal edilen robotik kodlama eğitim setleri, uygulama ve kullanım kolaylığı sunmakta, ancak; Milli Eğitim Bakanlığı'na bağlı kurumların sınırlı bütçesi (Çoban, 2018) 
nedeniyle, bu pahalı setlerden sınırlı sayıda satın alınabilmektedir. Bu setlerden satın alabilen okullar ise setin kullanımına yönelik eğitmen eğitimleri için yine büyük masraflara katlanmak zorunda kalmaktadırlar. Bu durum, robotik kodlama eğitimiyle ülkemizin hedeflediği noktaya ulaşabilmesinin önündeki engellerden biri olarak kabul edilebilir.

Robotik kodlama eğitimi üzerine literatürde tarama yapıldığında, birçok uluslararası çalışmada (Rathy, Balaji ve Nadu, 2018; Martn-Ramos vd., 2018; McCullen ve Walters, 2018) Arduino tabanlı eğitim setlerinin kullanıldığı görülmektedir. Arduino, açık kaynak kodlu olması sayesinde geliştiricilere birçok firsat sunmaktadır (Kasalak, 2017). Ancak; Arduino ile yapılan robotik kodlama, hem elektronik devre bilgisi hem de programlama bilgisi gerektirmektedir. $\mathrm{Bu}$ noktada, robot programlama eğitiminde birer engel olarak karşımıza çıkan durumların (öğrencilere soyut kavram öğretme zorluğu ve programlamanın gençlerin ilgi alanlarına hitap etmemesi vb.), MIT Yaşam Boyu Okul Öncesi Grubu tarafından hazırlanan Scratch isimli yazılım ile aşılabildiğine ilişkin araştırmalar bulunmaktadır (Yükseltürk ve Altıok, 2016). Çatlak, Tekdal ve Baz (2015) tarafından 32 makale ile gerçekleştirilen doküman inceleme çalışmasında, Scratch yazılımının programlama öğretiminde etkili olduğu, programlamayı daha zevkli ve anlaşılır hale getirdiği, ayrıca programlama eğitiminde ilgi ve motivasyonu artırdığı bulgularına ulaşılmıştır. Dolayısıyla, günümüzde kurumların kendi eğitim robotlarını Arduino ve Scratch gibi açık kaynak kodlu devre kartı ve yazılımlarıyla yapabilecekleri ve bu robotlarla da etkili bir șekilde robotik kodlama öğretimi yapılabileceği söylenebilir.

Bu araştırmada, ekonomik ve işlevsel bir robotik eğitim seti geliştirilmesine yönelik; uygun bütçeli, temel düzeyde elektronik ve kodlama bilgisiyle programlanabilecek, yeni başlayanlar için kısa devre yapmayı önleyici ve açık kaynak kodlu bir devre kartına sahip, Scratch vb. uygulamalarla uyumlu çalışabilecek bir eğitim robotunun ortaya koyulması amaçlanmıştır. $\mathrm{Bu}$ amaç doğrultusunda; öğrencilerin üzerinde rahatlıkla çalışabileceği, devre kartı ve modüllerin bağlantısını görebileceği, taşınması ve temin edilmesi oldukça kolay, yurtdışı menşeili emsallerine oranla çok daha düşük maliyetli, robotik kodlama öğretiminin sağlanabileceği ve kamu kaynaklarının dışa akmasını azaltabilecek nitelikte olan bir robotik eğitim setinin (ARUbot) nasıl geliştirilebileceği araştırılmıştır.

\section{YÖNTEM}

$\mathrm{Bu}$ araștırma kapsamında materyalin (ARUbot) geliştirilmesi sürecinde, Sistem/Yazılım Proje Yönetim Modellerinden Şelale (waterfall) Modeli baz alınmıştır. Şelale modeline göre yapılan geliştirme çalışmalarında; sistem gereksinimleri (1), yazılım gereksinimleri (2), analiz (3), tasarım (4), kodlama (5), test ve entegrasyon (6), idame ve bakım (7) adımları takip edilmektedir (Gencer ve Kayacan, 2017). Bu 7 adımlık geliştirme sürecine ilişkin ayrıntılar ilgili başlıklar çerçevesinde aşağıda sunulmuştur.

\section{Sistem Gereksinimleri}

Geliştirme sürecinin bu aşamasında, robotik eğitim setinin geliştirilmesi için bir devre kartı ve bu devre kartıyla uyumlu çalışacak modüllerin belirlenmesi yoluna gidilmiştir. Bu noktada çalışmada, açık kaynak kodlu olması ve uygun bütçeyle temin edilebilmesi (Kasalak, 2017) nedeniyle Arduino isimli devre kartı ve modüllerinin kullanılmasına karar verilmiştir. Robotun elektronik aksamında ne kullanılacağı, ortaya koyulacak eğitim robotunun maliyetini doğrudan 
etkilediğinden, sistemin Arduino tabanlı geliştirilmesi bu noktada büyük bir maliyet avantajı sağlamıştır.

\section{Yazılım Gereksinimleri}

Bu aşamada, programlama için ihtiyaç duyulan yazılım noktasında Arduino'nun kendi web sitesinden (www.arduino.cc) ücretsiz olarak indirilebilen Arduino IDE isimli yazılımın kullanılması planlanmıştır. Bu yazılım kullanıcılara kendi kodlarını yazabilme ve hazır kod kütüphanelerini kullanabilme imkânı sunmaktadır. Ayrıca Arduino devre kartları, Scratch gibi yine ücretsiz ve blok mantığıyla programlama yapmaya izin veren yazılımlarla da uyumlu șekilde çalışabilmektedir. Dolayısıyla, çalışmada Arduino tabanlı geliştirme yapılması yoluna gidilmesiyle; programlama için ücretli bir yazılım gereksinimi sorunu da ortadan kaldırılabilmiş ve mevcut ücretsiz / açık kaynak kodlu yazılımlardan yararlanabilme avantajı sağlanmıştır.

\section{Analiz}

Çalışmanın analiz aşamasında;

- STEAM eğiminde kullanılan piyasadaki robotlar ve özellikleri incelenmiş,

- Robotlardaki STEAM ile ilişkili özellikler incelenmiş,

- Robotların avantajları, üstünlükleri, sınırlılıkları, kullanım zorlukları ve eksiklikleri incelenmiş,

- Geliştirilecek prototipte bulunacak sensor ve modüllerin listesi çlkarılmıştır.

Bu kapsamda, mevcut robotlar üzerinde yapılan incelemelerin ardından, ARUbot'un sahip olacağı modüllerin listesi çıkarılmıştır. Bu aşamada mevcut eğitim robotları ve robotlarda bulunan modüllerin maliyetleri dikkate alınmıştır. Ardından uygun bütçeli ve birbiriyle uyumlu çalışabilecek modüllerin belirlenmesi yoluna gidilmiştir. Bu noktada, eğitim robotunda bulunması planlanan devre kartı modeli ve modüllerin listesi aşağıda işlevleriyle birlikte sunulmuştur.

- Arduino UNO devre kartı: Tüm modüllerin takılacağı programlanabilir devre kartıdır.

- Ultrasonic mesafe sensoru: Engellere olan uzaklı̆̆ı ölçebilecektir.

- Servo motor: Ultrasoic mesafe sensorunu sağa-sola çevirebilecektir.

- LCD ekran: Ekranda mesaj gösterilebilecektir.

- Bluetooth kartı: Cep telefonu veya bilgisayardan kontrol edilebilecektir.

- RGB Led: Birçok renkte ışığı tek lambayla verebilecektir.

- Buzzer: Farkli tonlarda ses verebilecektir.

- DHT22 isı ve nem sensoru: Ortamın ısı ve nemini ölçebilecektir.

- LDR modülü: Aydınlık ve karanlık durumunu algılayabilecektir.

- Push button: Aç/kapat işlevlerini yapabilecektir.

- TCRT5000 kızılötesi sensoru: Çizgi izlemede renkleri kızılötesiyle algılayabilecektir.

- 9V'luk pil ve pil kutusu: Fiyat avantajı nedeniyle 9V'luk pil ile çalışabilecektir.

- Motor ve sürücü kartı: Íki adet motor ve bir adet motor sürücü kartıyla 360 derece hareket edebilecektir.

- Motor, kızılötesi, bluetooth ve ekran için birer aç/kapat butonu: Kullanılmayan modüllerin pilden akım çekmemesi için aç/kapat işlevi butonla sağlanabilecektir. 
- Tekerlekler ve şase: Zeminde tutuş avantajı nedeniyle paletli tekerleklere ve modüllerin sığabileceği minimum ebatta şaseye sahip olacak ve bunlar 3D yazıcıdan basılacaktır.

Yurtdışından ithal edilen paletli robot setleri ile yukarıda listesi verilen modüllerden oluşması planlanan ARUbot'un maliyet açısından karşılaştırılması neticesinde, daha fazla modül bulundurmasına rağmen ARUbot'un emsallerinden yaklaşık sekiz kat daha ucuza mal olacağı anlaşılmıştır. Böylece, çalışmada analiz aşaması sonlandırılmış ve planlanan devre elemanlarını barındırabilecek bir tasarımın oluşturulması aşamasına geçilmiştir.

\section{Tasarım}

Çalışmanın tasarım aşamasında; Arduino devre kartı ve modüllerinden oluşan ve tüm bileşenlerin birbiriyle uyumlu şekilde çalışabildiği bir sistemin nasıl olabileceğine odaklanılmıştır. $\mathrm{Bu}$ noktada, öncelikle analiz aşamasında belirlenen bileșenlerin büyük boy bir breadboard üzerinde çalışır hale getirilmesi yoluna gidilmiştir. Kullanılması planlanan tüm modüllerin Arduino devre kartı üzerinde birbirleriyle uyum içerisinde çalışabileceği bir bağlantı şeklinin belirlenmesi noktasında yapay zekayla devre tasarımı yapan bazı uygulamalara başvurulmuş, ancak bu uygulamaların tüm modül bağlantılarını yapabilme konusunda yetersiz kaldıkları görülmüştür. Bu noktada, Arduino UNO modeli üzerinde tüm modüllerin birbiriyle uyumlu bir şekilde çalışabileceği bir devre tasarımı araştırmacılar tarafından yapılabilmiştir. Devre tasarımı yapılırken açık kaynak kodlu bir uygulama kullanılmış ve oluşturulan devre tasarımı aşağıda yer alan Şekil 1'de sunulmuştur.

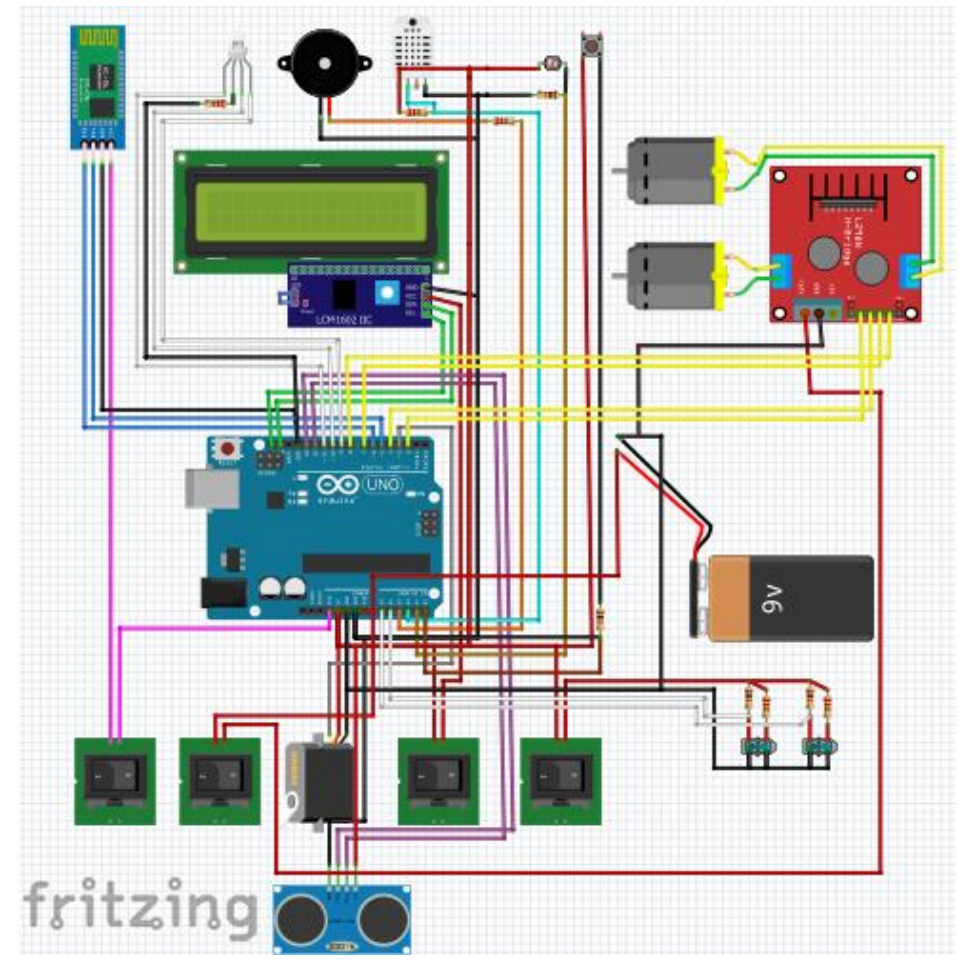

Şekil 1: Tüm Modüllerin Bağlantılarını Gösteren Devre Tasarımı

Şekil 1 incelendiğinde, çalışmada planlanan tüm modüllerin Arduino UNO kart üzerindeki analog ve dijital bağlantı noktaları kullanılarak bağlanabildiği görülmektedir. Devre tasarımının 
elektronik ortamda yapılmasının ardından tüm modül bağlantılarının gerçek ortamda yapılması aşamasına geçilmiştir. Bu aşamada tüm modüllerin yerleştirileceği bir şase tasarımının yapılması hedeflenmiş ve bu amaçla karton bir kutu üzerinde modüllerin şase üzerindeki konumu belirlenmeye çalışılmıştır. Tüm modüllerin tasarlanan devre doğrultusunda fiziksel olarak bağlantılarının yapılmış versiyonu ve bu modüllerin yerleştirilebileceği şase tasarımı için plot uygulamanın yapıldığı karton kutunun fotoğrafı aşağıda yer alan Şekil 2'de sunulmuştur.

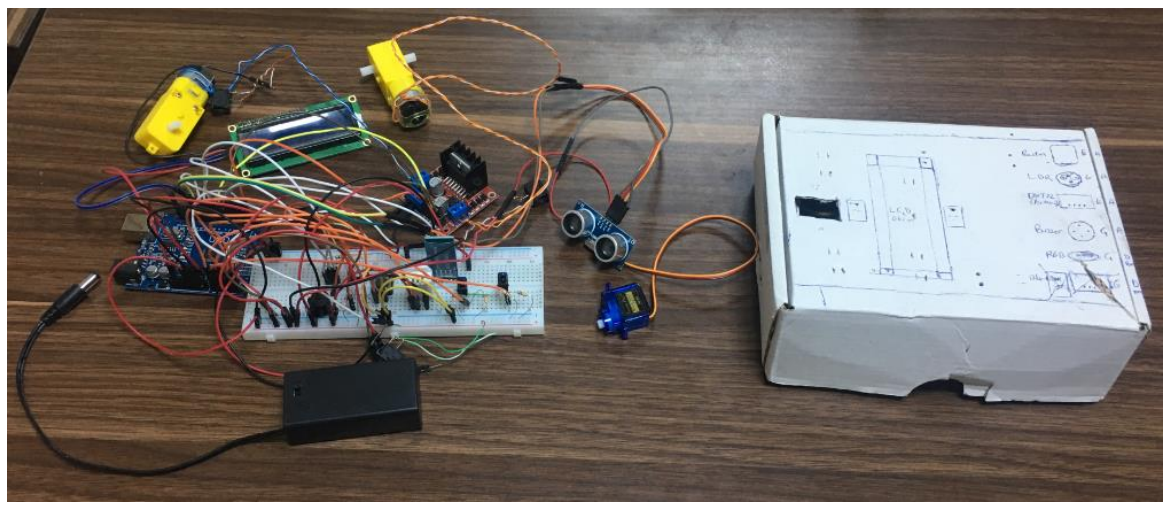

Şekil 2: Şase İçin Kartondan Yapılan Tasarım

Şekil 2'de sunulan kartondan şase tasarımı ARUbot'un ebatları hakkında ön bilgi edinebilme noktasında önemli dönüt sağlamıştır. Böylece, tüm bileşenlerin yerleştirilebileceği minimum boyutlu bir şasenin ölçüleri ortaya çıkarılabilmiştir. Ardından, 3D yazıcıdan çıkarılabilmesi amacıyla şasenin 3D ortamda tasarımının yapılması yoluna gidilmiştir. Bu aşamada yine ücretsiz olan ve Tinkercad.com adresi üzerinden web tabanlı çalışan bir 3D çizim uygulamasıyla şase tasarımı yapılmıştır. Yapılan bu tasarım aşağıda yer alan Şekil 3'te sunulmuştur.

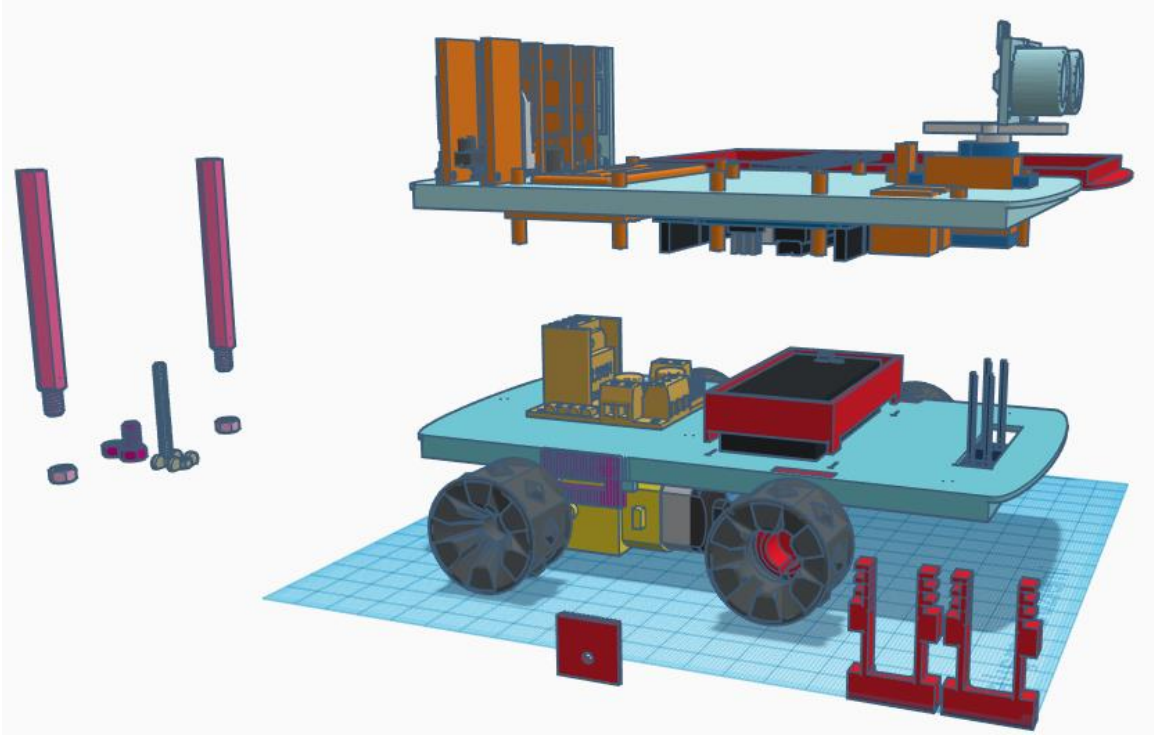

Şekil 3: ARUbot'un Şase Tasarımı

Şekil 3 incelendiğinde, şase tasarımı yapılırken; devre kartı ve tüm modülleri tutabilecek, elektronik bağlantılar öğrenciler tarafından görülebilecek ve söküp takmaya izin verebilecek nitelikte olmasına özen gösterildiği anlaşılabilecektir. Gelecek çalışmalarda şase için öğrencilerin 
ilgisini çekebilecek bir tasarım yapılabilir, ancak bu çalışmada şase olarak Şekil 3'te sunulan 3D tasarımın kullanılması yoluna gidilmiștir.

Devre ve şase tasarımının tamamlanmasının ardından prototip üretimi aşamasına geçilmiş ve 3D yazıcıdan baskıların alınması ve montajın yapılmasıyla ilk ürün ortaya koyulmuştur. $\mathrm{Bu}$ prototipe ilişkin görseller ise Şekil 4 ve Şekil 5’te sunulmuştur.

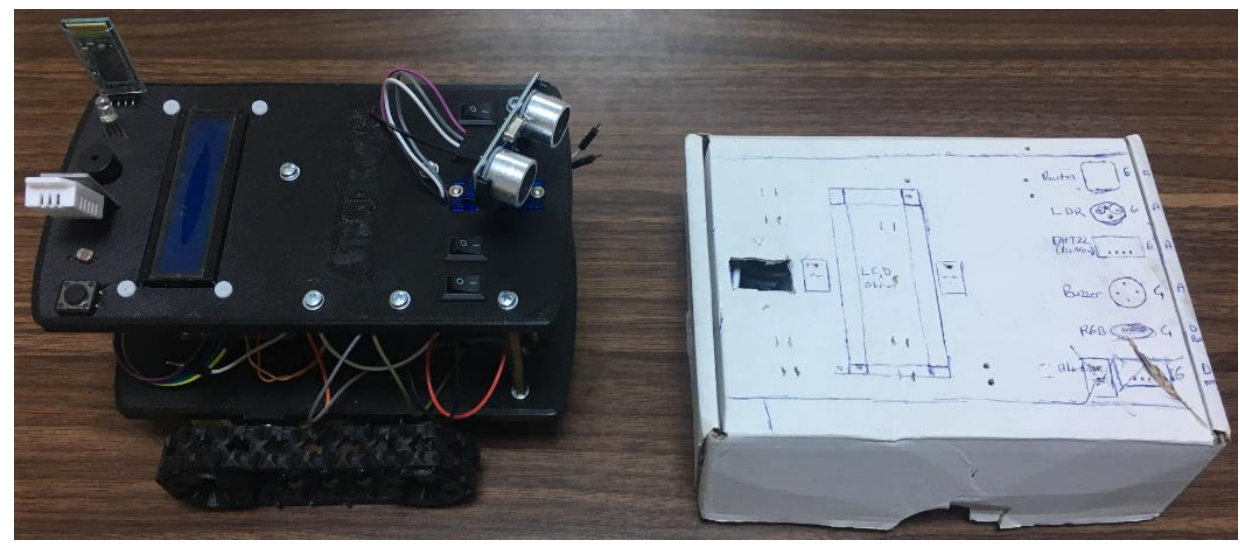

Şekil 4: ARUbot Prototipi

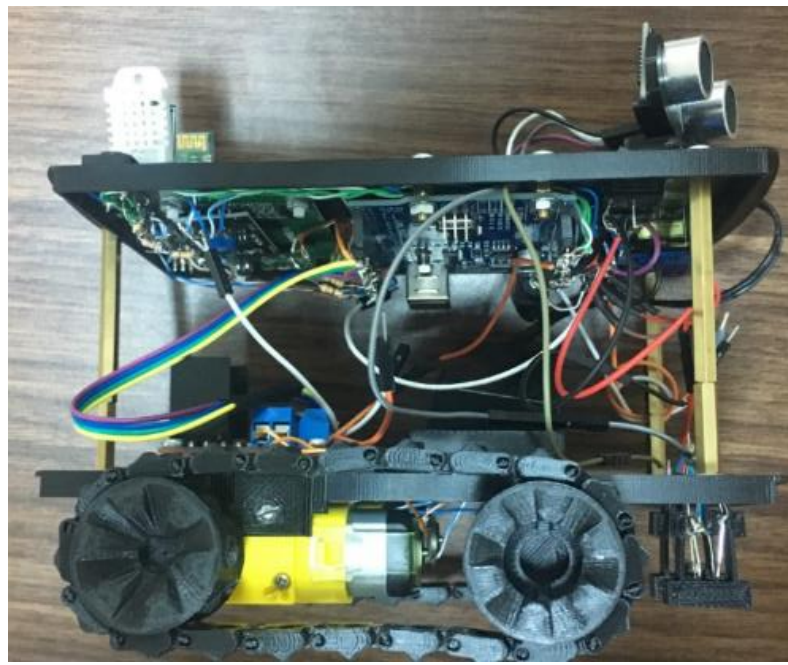

Şekil 5: Prototipte Devrelerin Görünümü

Yapılan planlamalar doğrultusunda üretilen prototipin üstten (Şekil 4) ve yandan (Şekil 5) görünümleri yukarıdaki görsellerde sunulmuştur. 3D yazıcıdan alınan baskının maliyetini düşürebilmek amacıyla bu projede alt ve üst tabaka $1 \mathrm{~mm}$ kalınlığında basılmıştır. Tabakaların esnememesi için kenarlar ise $4 \mathrm{~mm}^{2}$ 'lik hat ile çevrelenmiştir. Bu prototipte şase için siyah renk kullanılmıştır, ancak isteğe bağlı olarak renkli flament kullanılmasıyla 3D yazıcıdan farklı renklerde şase basılabilir.

\section{Kodlama}

Arduino'da kodlama işlemi Arduino'nun web sitesinden ücretsiz olarak indirilebilen Arduino IDE isimli uygulamayla yapılabilmektedir. Ayrıca, Scratch vb. blok tabanlı görsel programlama araçlarıyla hazırlanan uygulamaların kodları da aktarılabilmektedir. Dolayısıyla, 
kodlama noktasında kullanıcılara platform seçme özgürlügü sunulmaktadır.

$\mathrm{Bu}$ çalışma kapsamında öğrencilerin robotik kodlama öğrenmelerine katkıda bulunmak amacıyla her modül için örnek uygulamalar hazırlanmıştır. Bu uygulamaların kodları çalışmanın Ekler bölümünde sunulmuştur.

\section{Test ve Entegrasyon}

Üretilen prototip; araştırmacılar, öğretim elemanları ve üniversite adayı öğrenciler tarafından test edilmiştir. Prototip öncelikle araştırmacılar tarafından fiziksel bir testten geçirilmiştir. Küçük çaplı darbelere rağmen tüm modülerin sağlıklı şekilde çalışmaya devam ettiğinin anlaşılması üzerine Mühendislik Fakültesinde görev yapan 3 öğretim elemanının görüşlerine başvurulmuştur. Alınan olumlu dönütlerin ardından, Ardahan Üniversitesi Tanıtım Günleri etkinliğinde aday öğrencilere tanıtılmıștır. Tanıtım esnasında ARUbot üzerindeki tüm modüllerin birlikte kullanımı sonucunda 9V 200mAh gücündeki bir bataryanın 5 dakikada deşarj olduğu gözlenmiş ve bu sınırlılık test aşamasından elde edilen en önemli dönüt olarak kayda alınmıştır. Bu sınırlılığa rağmen alınan olumlu dönütlerin ardından test aşaması tamamlanmıştır.

\section{İdame ve Bakım}

ARUbot için sürekli ihtiyaç duyulan tek bakım bataryasının şarj edilmesidir. Bunun haricinde prototip için henüz bir bakım/onarım ihtiyacı doğmamıştır, ancak ilerleyen süreçte kötü/sert kullanıma bağlı olarak modüllerden veya lehimlerden kaynaklı arızalar olabilir. Bu gibi durumlar için ARUbot üst kapağı kaldırılarak kolaylıkla müdahale yapılabilecek şekilde tasarlanmıştır. Ayrıca, bakım işlemi için devre elemanlarının bağlantı şeması da kullanıcılarla paylaşılan yardım dokümanında yer almaktadır. Bakım yaparken üst tabladaki vidaların açılarak ARUbot içerisindeki devrelere kolaylıkla müdahale edilebileceğini gösteren görsel aşağıda yer alan Şekil 6'da sunulmuştur.

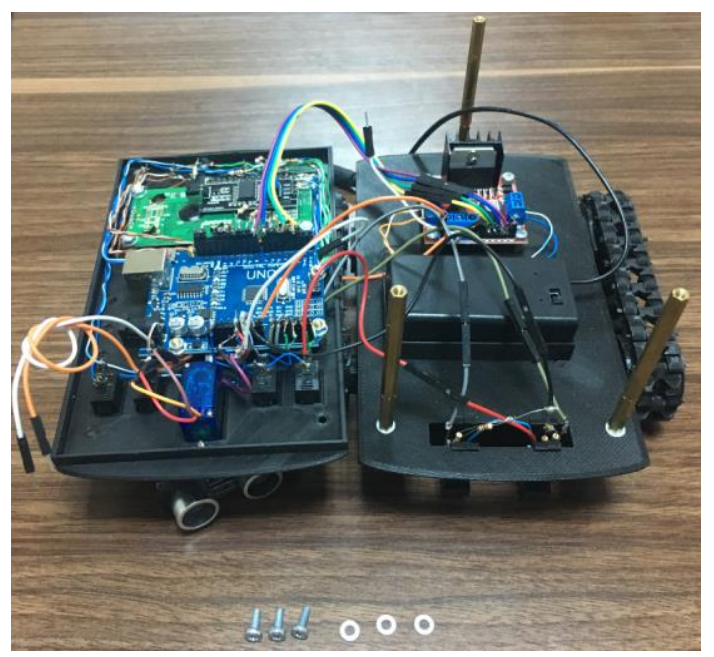

Şekil 6: ARUbot'un Bakım Modu

Şekil 6 incelendiğinde, prototip için ihtiyaç duyulacak bakım çalışmasına izin verecek şekilde bir şase tasarımı yapılmasına özen gösterildiği anlaşılacaktır. Bu noktada, mevcut şase tasarımı için gelecekte bir grafiker eliyle çok daha ilgi çekici bir tasarım yapılabilir.

Ürünün sürdürülebilirliği noktasında, Ardahan Üniversitesi'nin Mühendislik Fakültesi 
bünyesinde Bilgisayar Mühendisliği ve Elektrik Elektronik Mühendisliği Bölümü ve Ardahan Teknik Bilimler MYO bünyesinde Bilgisayar Programcıllı̆g programı öğrencileri ve öğretim elemanlarının değerli katkılarıyla ARUbot'un geliştirme sürecinin devam edebileceği söylenebilir.

\section{BULGULAR ve TARTIŞMA}

$\mathrm{Bu}$ çalışma kapsamında; elektronik ve robotik kodlama eğitiminde kullanılabilecek, programlanması basit, kısa devre korumalı, yazarak veya blok tabanlı kodlanabilen, modül bağlantılarının kolayca görülebildiği, lisanslama ve telif hakkı sorunu bulunmayan, düşük maliyetli ve kamu kaynaklarının dışa akmasını azaltabilecek nitelikte bir robotik eğitim seti oluşturulması hedeflenmiştir. Bu amaca yönelik yapılan geliştirme çalışması neticesinde ulaşılan bulgular aşağıda tasarım (1.1.), maliyet (1.2.) ve yapılabilecek uygulamalar (1.3.) başlıkları çerçevesinde sunulmuştur.

\section{Tasarıma İlişkin Bulgular}

$\mathrm{Bu}$ çalışmada tasarıma ilişkin bulguların elde edilmesinde kullanılan veriler; araştırmacıların deneyimleri, literatürdeki ilgili çalışmalar ve piyasadaki mevcut eğitim setlerinden toplanmıştır. Öncelikle çalışmada uygun tasarımın ortaya koyulabilmesi için tüm devre elemanlarının bağlanacağı ana devre kartının belirlenmesi yoluna gidilmiştir. Bu amaçla; literatürdeki çalışmalar, piyasadaki mevcut eğitim setleri ve robotik kodlama devre kartları incelenmiştir. Bu inceleme neticesinde; açık kaynak kodlu olması, kısa devre koruması bulunması, maliyetinin düşük olması, blok tabanlı kodlamaya izin vermesi gibi daha birçok avantaj sunması nedeniyle, geliştirilecek robotik eğitim setinin devre kartında Arduino kullanılması planlanmıştır. Literatürde yer alan STEM becerilerinin geliştirilmesine yönelik çalışmalar (Keenan vd., 2019; Ling ve Wah, 2019; Plaza vd., 2019) incelendiğinde Arduino tabanlı eğitim robotlarının bu amaç için uygun olacağının belirtildiği görülmüştür. Ayrıca, Çömek ve Avcı (2016) Arduino üzerine öğretmen ve öğrenci görüşlerini incelediği çalışmasında, elektronik ve kodlama öğretimi noktasında Arduino'nun kolaylık sağladığını ortaya koymuştur. Dolayısıyla, bu gibi çalıșmalarda Arduino devre kartı ve modülleri kullanılmasının literatürle de uyuştuğu söylenebilir.

ARUbot'un temel bileșeni olarak Arduino'nun belirlenmesinin ardından, ARUbot'ta bulunacak modüllerin belirlenmesi aşamasına geçilmiştir. Bu aşamada ARUbot üzerinde bulunacak modüller belirlenirken; Arduino'nun desteklediği birçok modül arasından STEM eğitiminin başlangıç düzeyinde kullanılan ve birbiriyle uyumlu şekilde çalışabilecek modüllere öncelik verilmiştir. Bu çerçevede ARUbot üzerinde 11 adet modül bulunması planlanmış ve planlanan bu modüllerin listesi aşağıda yer alan Tablo 1'de sunulmuştur.

Tablo 1: ARUbot'un Modülleri

ARUbot Üzerinde Bulunması Planlanan 11 Adet Modül

\begin{tabular}{ll} 
1. Ultrasonic mesafe sensoru & 7. DHT22 ıSı ve nem sensoru \\
2. Servo motor & 8. LDR modülü \\
3. LCD ekran & 9. Push button \\
4. Bluetooth kartı & 10. TCRT5000 kızllötesi sensoru \\
5. RGB Led & 11. Motor ve sürücü kartı \\
6. Buzzer & \\
\hline
\end{tabular}

Tablo 1'de listesi verilen modüllerin ARUbot üzerinde bağlantılarının yapılması ve 
kullanıma hazır hale getirilmesi planlanmıștır. Kullanılan bataryanın doluluk oranına göre bu 11 adet modülün aynı anda kullanılması ve birbiriyle uyumlu şekilde çalışması mümkündür, ancak; kullanım süresinin bataryanın gücüyle sınırlı olacă̆ı göz ardı edilmemelidir.

Modüllerin seçilmesinden sonra tüm bu modüllerin hangi Arduino devre kartı modeliyle birlikte kullanılabileceğinin belirlenmesi aşamasına geçilmiştir. Bu aşamada, yapılan denemeler sonucunda Arduino UNO modeliyle tüm bu modüllerin bir arada çalıștırılabildiği bulgusuna ulaşılmıştır. Tüm modüllerin çalışabilmesi için Arduino UNO üzerindeki PIN’lere nasıl bağlantı yapılabileceği noktasında ulaşılan bulgu aşağıda yer alan Tablo 2'de verilmiștir.

Tablo 2: Arduino UNO Üzerinde Modüllerin PIN Bağlantıları

\begin{tabular}{ll|llll}
\hline \multicolumn{2}{c|}{ Analog PIN Bağlantıları } & \multicolumn{4}{c}{ Dijital PIN Bağlantıları } \\
\hline A0 & TCRT5000 (Soldaki) & 2 & Sürücü Kartı (1. Motor) & 9 & RGB Led (Mavi) \\
A1 & TCRT5000 (Sağdaki) & 3 & Servo Motor & 10 & RGB Led (Yeşil) \\
A2 & Buzzer & 4 & Sürücü Kartı (1. Motor) & 11 & RGB Led (Kırmızı) \\
A3 & DHT22 & 5 & Bluetooth (TX) & 12 & Ultrasonic (trig) \\
A4 & LDR & 6 & Bluetooth (RX) & 13 & Ultrasonic (echo) \\
A5 & Button & 7 & Sürücü Kartı (2. Motor) & SCL & LCD Ekran \\
& & 8 & Sürücü Kartı (2. Motor) & SDA & LCD Ekran \\
\hline
\end{tabular}

Tablo 2 incelendiğinde; Arduino UNO üzerindeki tüm analog portlar ve iki tanesi haricindeki tüm dijital portların kullanıldığı görülmektedir. Kullanılmayan bu iki dijital PIN ise 0 (RX) ve 1 (TX) portlarıdır. Yazılan kodlar Arduino devre kartına aktarılırken 0 (sıfır) numaralı dijital port kullanıldığından, kod aktarma işlemi sırasında bu porta bağlı bir modül olmaması gerekmektedir. Bu nedenle, her kod aktarma işleminde kullanıcının sökme-takma işlemiyle uğraşmaması için 0 (sıfır) ve 1 (bir) numaralı PIN’ler boş bırakılmıştır.

Devre kartı ve modüllerin belirlenmesinin ardından, ARUbot isimli robotik kodlama eğitim setinin prototip üretimi aşamasına geçilmiştir. Bu aşamada vücut bulan ARUbot'un dış görünüşü (Şekil 7) ve iç görünüşüne (Şekil 8) ilişkin görseller aşağıda sunulmuştur.

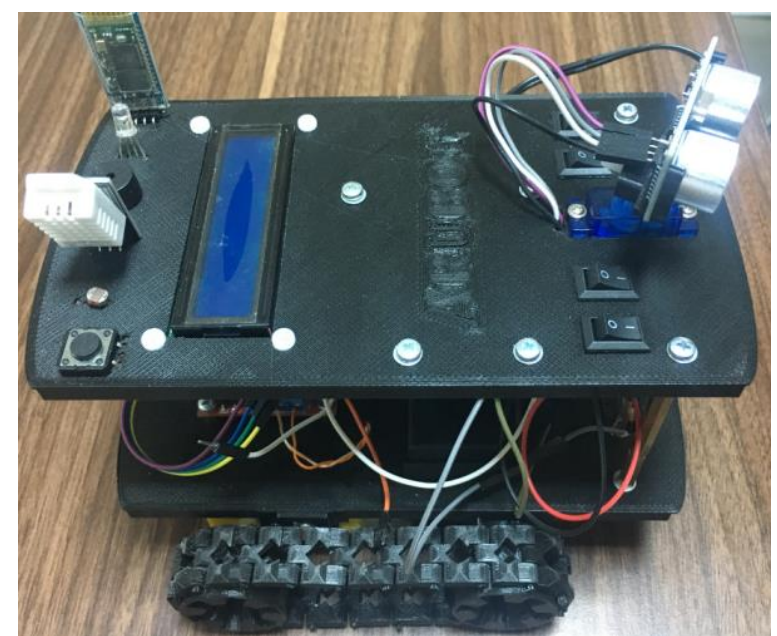

Şekil 7: ARUbot'un Dış Tasarımı

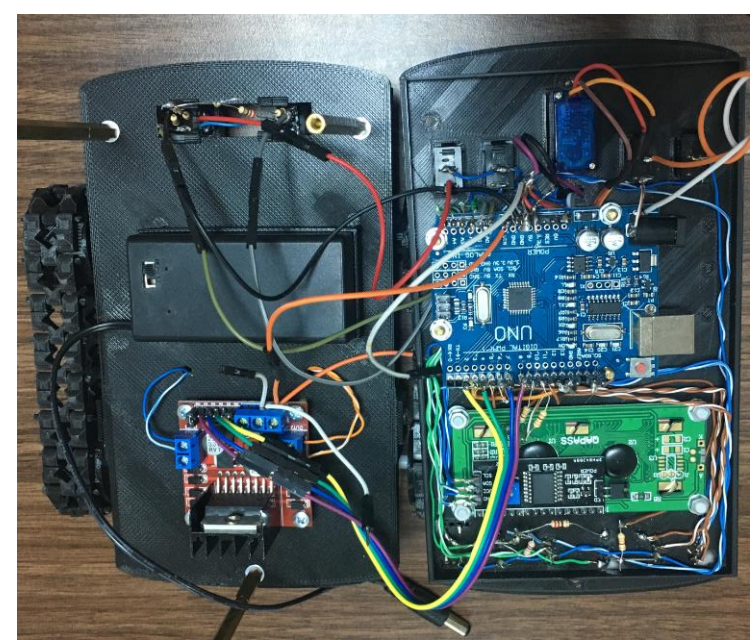

Şekil 8: ARUbot'un İç Tasarımı

Şekil 7 ve Şekil 8'de, çalışmanın amacı doğrultusunda hedeflenen özellikleri taşıyan, elektronik ve robotik kodlama eğitiminde kullanılabilecek bir robotun nasıl olabileceğine yönelik somut bir prototip ortaya koyulmuştur. Bu prototip, kurumların kendi eğitim robotlarını nasıl 
geliştirebilecekleri ve bu geliştirmenin ne kadarlık bir maliyet ile yapılabileceği noktasında yol gösterici niteliktedir.

\section{Maliyete İlişkin Bulgular}

Çalışma kapsamında geliştirilen robotun maliyetini hesaplayabilmek için kullanılan tüm bileşenlerin maliyeti hesaplamaya katılmıştır. Bileşenlerin Türk Lirası (TL) cinsinden karşllı̆̆ aşağıda yer alan Tablo 3'te sunulmuştur.

Tablo 3: ARUbot'un Maliyet Bilgisi

\begin{tabular}{lc}
\hline Bileşen Adı & Yaklaşık Maliyeti' $\mathbf{~ ( T L ) ~}$ \\
\hline Arduino UNO devre kartı & 22,00 \\
Ultrasonic mesafe sensoru & 6,49 \\
Servo motor & 9,10 \\
LCD ekran & 13,00 \\
Bluetooth kartı & 24,40 \\
RGB Led & 0,35 \\
Buzzer & 0,79 \\
DHT22 ısı ve nem sensoru & 25,00 \\
LDR modülü & 0,30 \\
Push button & 0,15 \\
TCRT5000 kızılötesi sensoru & 0,86 \\
9V'luk pil & 13,90 \\
9V'luk pil kutusu & 8,95 \\
Motor (2 adet) & 14,10 \\
Motor sürücü kartı & 11,00 \\
Motor, klzılötesi, bluetooth ve ekran için birer push button $(4$ & 0,60 \\
adet) & \\
Tekerlekler, şase ve pil tutacağı (flament) & 10,00 \\
Lehim teli & 1,00 \\
M3 metal aralayıcı (3 adet) & 10,62 \\
M3 Vida ve somunlar (10 adet) & 1,99 \\
Dirençler (2 adet 10'lu paket) & 0,48 \\
\hline Toplam & $\mathbf{1 7 5 , 0 8}$ \\
\hline
\end{tabular}

Tablo 3 incelendiğinde, ARUbot isimli Ardahan Üniversitesi elektronik ve robotik kodlama eğitim robotunun yaklaşık 175TL $(\sim 29,7$ ) bir maliyeti olduğu anlaşılmaktadır. ARUbot'un üzerinde 11 adet modül bulunması ve paletli tasarımı dikkate alındığında, yurtdışı menşeili emsallerinden yaklaşık 8 kat daha uyguna mal olduğu görülmektedir. Dolayısıyla, kurumların kendi eğitim robotlarını geliştirmeleri durumunda, oldukça az bir bütçeyle bu ihtiyaçlarını karşılayabilecekleri bulgusuna ulaşılmıştır. Bu bulgu, Yang ve arkadaşları (2019) tarafından yapılan çalışmada Arduino'nun düşük maliyetine dikkat çekilmesi boyutuyla da desteklenmektedir.

\footnotetext{
2 Ürünlerin fiyat bilgisi 16/06/2019 tarihinde N11.com isimli alışveriş sitesinden alınmıştır. Bu tarihte Türkiye Cumhuriyet Merkez Bankası USD/TRY alış/satış kapanış kuru 5.8826/5.8932'dir.
} 


\section{ARUbot ile Yapılabilecek Uygulamalara İlişkin Bulgular}

ARUbot üzerinde listesi yukarıda verilen (Tablo 1) 11 adet modül bulunmaktadır. $\mathrm{Bu}$ modüller tek tek veya birlikte kullanılabilmektedir. Dolayısıyla, 11 modülün farklı kombinasyonlarıyla matematiksel olarak (211-1) 2047 farklı kullanım şekli elde edilebilmektedir. Örneğin motor sürücü kartı; bluetooth kartıyla birlikte kullanıldığında cep telefonundan kumanda edilebilen araba, ultrasonic mesafe sensoru ile birlikte kullanıldığında engelden kaçan araba, TCRT5000 ile birlikte kullanıldığında ise çizgi izleyen araba olabilmektedir. Dolayısıyla, bu örneklerdeki gibi ikili modül kullanımıyla bile ARUbot çeşitli işlevleri yerine getirebilen bir robota dönüşebilmektedir. Daha fazla sayıda modülün bir arada kullanılması sayesinde ise çok daha farklı uygulamaların geliştirilebilmesi söz konusudur. Dolayısıyla, yapılabilecek uygulamalar bir anlamda öğrencilerin hayal gücüyle ve becerisiyle sınırlıdır.

Çalışma kapsamında öğrencilerin yararlanabilmesi amacıyla her modülün nasıl kullanılabileceğine ilişkin örnek uygulama kodları hazırlanmıştır. Toplam 11 adet modülün kullanımına ilişkin örnek kodlar çalışmanın Ekler bölümünde sunulmuştur.

\section{SONUÇ}

Günümüzde STEAM eğitimlerinin (Science, Technology, Engineering, Art, Mathematics) yaygınlaşması ve bilgi işlemsel düşünce becerilerinin iyileştirilmesi gibi son zamanlarda öne çıkan eğitim anlayışları, robot setleri üzerinden birtakım uygulamaların ve deneylerin yapılmasını yaygınlaştırmıştır. Son zamanlarda bu konuda farklı desteklerle yapılan çok sayıda çalışmanın olduğu görülmektedir. Ancak, bu hızlı eğitim geçişi ile aslında özellikle yurt dışı menşeili hazır robot ve uygulama satan firmaların bir tüketicisi olmanın önüne geçilememiştir. Yurtdışında tasarlanmış ve ithal edilen, fiyatları da 100 - 1000 aralığında veya daha da üzerinde olan setlerin satın alınması; kamu kaynaklarının yurtdışına akmasına, kısa süreli eğitimlerde kullanmak üzere âtıl yatırımlara dönüşmesine ve yeni başlayanlar tarafından kısa devre yapılarak cihazın yanabilmesi gibi sorunlara yol açmaktadır. Bu sorunlara eklenebilecek diğer ifadeler, temin edilen robot setlerinin; pahalı olması, her ortamda ve disiplinde kullanılamaması, üzerine ekleme yaparak geliştirilmeye müsait olmaması, eğitmen eğitimlerinin maliyetli olması ve yeni başlayanlar için pratik olmaması gibidir. Bu sorunlar STEAM için beklenen etkinin oluşmasını engellediği gibi ülkemizi de dışa bağımlı hale getirmektedir.

Robotik kodlama eğitiminde amaç hazır robot setlerinin satın alınarak sınıf ortamına getirilmesi değildir. Ayrıca, eğitim sistemine teknoloji entegrasyonu, bir teknolojinin sadece satın alınarak sınıf ortamına getirilmesi anlamına gelmez (Topuz ve Göktaş, 2015). Robotik kodlama, öğrencilerin; bilişsel, duyuşsal ve psikomotor becerilerinin bir arada geliştirilmesinde kullanılabilecek bir eğitim teknolojisi aracıdır. Ancak, bazı hazır setler ve ileri elektronik bilgi gerektiren devreler ile öğrencilerde böyle bir gelişim söz konusu olamamaktadır. Öğrenciler elektronik devre bilgisine boğulmadan hızlı ve kolay bir şekilde robotik kodlamayı öğrenebilmeli ve akabinde asıl amaç olarak STEAM kapsamındaki konulara yönelik deneyleri yaparak öğrenebilmelidir. Böylece yapılandırmacı yaklaşım kapsamında öğrencilere kendi bilgi ve becerilerini oluşturabilme fırsatı sunulabilmiş olur.

Bu düşünceyle çalışmada; elektronik ve robotik kodlama eğitiminde kullanılabilecek ve kolay programlanabilen bir robotik eğitim setinin nasıl olabileceği araştırılmış ve bu kapsamda ARUbot isimli robot üretilmiştir. ARUbot üzerinde bulunan 11 adet modül ile kullanıcılara 2047 
farklı uygulama geliștirme imkânı sunulabilmektedir. Dolayısıyla, öğrencilere kendi hayal gücüyle deneyler ve uygulamalar yapabilecekleri bir robot sunulmaktadır. Üstelik bu robotun maliyeti ise sadece yaklaşı 175TL ( 29,7\$) olmuştur. Böyle bir robotun kurum tarafından geliştirilmesi, yurtdışı menşeili emsallerinden satın almaktan yaklaşık 8 kat maliyet avantajı sağlamıştır. Ayrıca robotik eğitim setlerinin satın alınması noktasında yurtdışına akan kamu kaynakları da önemli ölçüde azaltılabilir. Bu bakış açısıyla, ülkemizde FeTeMM eğitimine yol gösterici nitelikte bir ürün ortaya koyulduğu söylenebilir. Ürünün maliyet boyutu değerlendirilirken, ilk üretim için 3D yazıcıdan havyaya kadar birçok cihazın satın alındığı, ancak hesaplanan maliyete bu cihazların dahil edilmediği göz ardı edilmemelidir.

Çalışma kapsamında öğrencilerin hayal ettikleri robota hayat verirken ihtiyaç duyabilecekleri sensörler ve modüllerin kullanımına ilișkin örnek kodlar hazırlanmıștır. Bu hazır kodlar sayesinde öğrencilerin ihtiyaç duydukları kodlama bilgisine hızlı ve kolayca ulaşabilmesi sağlandığından, internetteki bilgi kirliliği arasında kaybolmalarının da önüne geçilebileceği söylenebilir. Çalışmanın Ekler bölümünde sunulan bu kodlar sayesinde hedeflenen çıtıların alınabilmesi noktasında önemli bir katkı sunulduğu düşünülmektedir.

Sonuç olarak, bu çalışma ile elektronik ve robotik kodlama öğretiminde kullanılabilecek uygun bütçeli bir robotik eğitim setinin; nasıl tasarlanabileceği, ne kadara mal edilebileceği ve hangi uygulamaların yapılabileceğine yönelik bulgular doğrultusunda, kurumların kendi setlerini nasıl geliştirebilecekleri noktasında literature katkı sunulduğu söylenebilir. Öğrenciler ARUbot gibi kitler sayesinde kendi robotlarını geliștirmeyi öğrenebilir ve sonraki aşamada ise ulusal ve uluslararası düzeydeki yarışmalara katılabilirler.

\section{ÖNERILER}

Çalışma kapsamında kazanılan deneyimler doğrultusunda, kendi robotunu geliştirmek isteyen kurumlara, sistem geliştiricilerine ve gelecek araştırmalara yönelik öneriler aşağıda gruplanarak maddeler halinde sunulmuştur.

\section{Kendi robotunu geliştirmek isteyen kurumlara ve sistem geliştiricilerine yönelik öneriler:}

- $\mathrm{Bu}$ projede modül ve sensörlerin Arduino devre kartına bağlantısı bakır kablolarla yapılmıştır. Bu noktada, bir baskı devre hazırlanarak Arduino ve diğer bileşenlerin daha düzenli bir şekilde bağlantısı sağlanabilir.

- Bazı kaynaklarda modüllerin ya sadece analog ya da sadece dijital PIN’lere takılabileceği belirtilmektedir. Ancak, bu bilginin doğru olmadığı ve birçok modülün hem analog hem de dijital PIN’lere takılabileceği, bu çalışma kapsamında alan yazına kazandırılan önemli bir bilgidir. Hangi modüllerin hangi PIN'lere bağlanabileceği noktasında bu çalışmanın tasarıma ilişkin bulgularından yararlanılabilir.

- Yapılan testlerde pil tüketimine en fazla motor kullanmanın neden olduğu görülmüştür. Motor kullanımının ağırlıklı olmayacağı robotlarda bu projede olduğu gibi 9V'luk uygun bütçeli bataryalar kullanılabilir.

- 3D yazıcıdan alınan baskının maliyetini düşürebilmek amacıyla bu projede alt ve üst tabaka $1 \mathrm{~mm}$ kalınlığında basılmıștır. Tabakaların esnememesi için kenarlar ise $4 \mathrm{~mm}^{2}$ lik 
hat ile çevrelenmiştir. Baskı maliyetini düşürebilmek için bu yöntemin kullanılabileceği söylenebilir.

- Robot üzerinde bulunan modül ve sensorler, arıza durumunda kolaylıkla değiştirilebilmelidir. Bu hususun, tasarım ve lehimleme işlemi yapılırken önem arz ettiği söylenebilir.

\section{Gelecek araştırmalara yönelik öneriler:}

- Test aşamasında projede kullanılan bataryanın ARUbot üzerindeki tüm modülleri birden sadece 5 dakika çalıştırabildiği görülmüştür. Ancak, kapasitesi yüksek olan bataryaların maliyeti de oldukça yüksektir. Bu noktada, hem uygun bütçeli hem de uzun süre kullanım sağlayabilecek çözümlerin araştırılacağı yeni çalışmalar yapılabilir.

- Arduino UNO isimli açık kaynak kodlu devre kartının çalışmanın amacı doğrultusunda kullanılabileceği görülmüştür. $\mathrm{Bu}$ noktada, başka hangi devre kartlarının kullanılabileceğinin araştırıldığı yeni çalışmalar yapılabilir.

- ARUbot'un şase tasarımı öğrenci için daha ilgi çekici hale getirilebilir. Bu noktada, öğrencilerin dikkatini/ilgisini çekebilecek bir robot şasesinin nasıl tasarlanabileceğine yönelik çalışmalar yapılabilir.

- ARUbot gibi kurumlar tarafından üretilen robotlar kullanılarak verilecek elektronik ve robotik kodlama eğitiminin etkililiğine ilişkin veya bu robotların kullanılabilirliğine yönelik yeni çalışmaları yapılabilir.

\section{KAYNAKÇA}

Akgündüz, D., Aydeniz, M., Çakmakçı, G., Çavaş, B., Çorlu, M. S., Öner, T., \& Özdemir, S. (2015). STEM eğitimi Türkiye raporu. İstanbul: Scala Basım.

An, G., Yang, Y., Wang, J., \& Du, X. (2019). A Study on the Effects to Students' STEM Academic Achievement with Chinese Parents' Participative Styles in School Education. Kuram ve Uygulamada Egitim Bilimleri, 19(1), 41-54.

Colucci-Gray, L., Burnard, P., Gray, D. S., \& Cooke, C. F. (2019). STEAM (Science, Technology, Engineering, Mathematics+ Arts). Re-visioning Education?. In Oxford Research Encyclopedia of Education (pp. 126). OUP Oxford.

Çatlak, Ş., Tekdal, M., \& Baz, F. Ç. (2015). Scratch yazılımı ile programlama öğretiminin durumu: Bir doküman inceleme çalışması. Journal of Instructional Technologies \& Teacher Education, 4(3), 13-25.

Çoban, G. S. (2018). Bilim ve Sanat Merkezleri Yöneticilerinin Yaşadıkları Zorluklar ve Çözüm Yollarına İlişkin Görüşleri: İstanbul Örneği (Doctoral dissertation, İstanbul Kültür Üniversitesi/Sosyal Bilimler Enstitüsü/Eğitim Bilimleri Anabilim Dalı).

Çömek, A., \& Avcı, B., (2016). Fen eğitiminde robotik uygulamaları hakkında öğretmen görüşleri. Uluslararası Yükseköğretimde Yeni Eğilimler Kongresi.

Gencer, C., \& Kayacan, A. (2017). Yazılım Proje Yönetimi: Şelale Modeli ve Çevik Yöntemlerin Karşılaştırılması. Biliş̧im Teknolojileri Dergisi, 10(3), 335-352.

Kasalak, İ. (2017). Robotik Kodlama Etkinliklerinin Ortaokul Öğrencilerinin Kodlamaya İlişkin Özyeterlik 
Algılarına Etkisi ve Etkinliklere İlişkin Öğrenci Yaşantıları (Yüksek Lisans Tezi, Hacettepe Üniversitesi).

Keenan, E., Shoushtarian, M., Karmakar, C. K., \& Palaniswami, M. (2019). Developing STEM skills using Arduino and heart rate variability analysis. Selected works, 47.

Ling, O. S., \& Wah, J. L. P. (2019). Ucts Foundation Students'perception Towards Arduino as a Teaching and Learning Tool in Stem Education. e-Bangi, 16(3).

Martn-Ramos, P., Lopes, M. J., Lima da Silva, M. M., Gomes, P. E., Pereira da Silva, P. S., Domingues, J. P., \& Ramos Silva, M. (2018). Reprint of First exposure to Arduino through peer-coaching. Computers in Human Behavior, 80(C), 420-427.

McCullen, K., \& Walters, M. (2018). Computer science and robotics using the raspberry pi, arduino, and other SBCS. journal of computing sciences in colleges, 33(6), 157-159.

Plaza, P., Sancristobal, E., Carro, G., Blazquez, M., García-Loro, F., Muñoz, M., ... \& Castro, M. (2019, April). STEM and Educational Robotics Using Scratch. In 2019 IEEE Global Engineering Education Conference (EDUCON) (pp. 330-336). IEEE.

Rathy, G. A., Balaji, A., \& Nadu, T. (2018). Arduino based 6DoF Robot using LabVIEW.

Suter, L. E., \& Camilli, G. (2019). International Student Achievement Comparisons and US STEM Workforce Development. Journal of Science Education and Technology, 28(1), 52-61.

Topuz, A. C., \& Göktaş, Y. (2015). Türk eğitim sisteminde teknolojinin etkin kullanımı için yapılan projeler: 1984-2013 dönemi. International Journal of Informatics Technologies, 8(2), 99.

Yang, S., Liu, Y., Wu, N., Zhang, Y., Svoronos, S., \& Pullammanappallil, P. (2019). Low-cost, Arduino-based, portable device for measurement of methane composition in biogas. Renewable Energy, 138, 224229.

Yükseltürk, E., \& Altıok, S. (2016). An investigation of the effects of programming with scratch. British Journal of Educational Technology. doi:10.1111/bjet.12453 


\section{Ek1) Tüm Modüllerin Kullanıma İlișkin Örnek Uygulama Kodları}

1) Bluetooth Kartı Kullanımına İlișkin Örnek Kodlar \#include < SoftwareSerial.h>

SoftwareSerial bluetooth_iletisim(6,5);

// bluetooth modülün TX,RX portlarına takınız

void setup()

$\{$ Serial.begin(9600);

bluetooth_iletisim.begin(9600);

void loop 0\{

if (bluetooth_iletisim.available() $>0$ )

$\{$ char data $=$ bluetooth_iletisim.read();

Serial.println(data); \}\}

\section{2) Button Kullanımına İlișkin Örnek Kodlar}

\#define butonPin A5

void setup() \{Serial.begin(9600);

void loop 0 \{

if(digitalRead(butonPin) $>0$ ) \{ Serial.println("basıldı"); delay(100);

\section{3) Buzzer Kullanımına İlișkin Örnek Kodlar} \#define buzzerPin A2

void setup $(0\{\}$

void loop 0\{

tone(buzzerPin,660)

delay(500);

noTone(buzzerPin);

delay(500); \}

\section{4) DHT22 Kullanımına İlișkin Örnek Kodlar} \#include "DHT.h"

\#define dht_apin A3

dht DHT;

void setup(0\{Serial.begin(9600);

void loop 0\{

DHT.read22(dht_apin);

Serial.print("Nem = ");

Serial.print(DHT.humidity);

Serial.print("\% ");

Serial.print("Sicaklık = ");

Serial.print(DHT.temperature);

Serial.println $\left({ }^{\circ} \mathrm{C}\right.$ ");

delay(2000);

\section{5) L298N Motor Kartı Kullanımına İlişkin Örnek Kodlar} const int in $1=2$; const int in $2=4$

const int in $3=7$; const int in $4=8$;

void setup ()\{

pinMode(in1, OUTPUT); pinMode(in2, OUTPUT);

pinMode(in3, OUTPUT); pinMode(in4, OUTPUT);

void loop 0 \{

$/ /$ motor 1

digitalWrite(in1, HIGH); digitalWrite(in2, LOW);

$/ /$ motor 2

digitalWrite(in3, HIGH); digitalWrite(in4, LOW);\}

\section{6) LCD Ekran Kullanımına İlișkin Örnek Kodlar}

\#include < LiquidCrystal_I2C_AvrI2C.h>

LiquidCrystal_I2C_AvrI2C Icd $(0 x 27,16,2)$;

// 20 karakter 4 satır için $(0 \times 27,20,4)$ yazılır

void setup()\{

lcd.begin();

//lcd.backlight();

//lcd.noBacklight0;

lcd.setCursor $(0,0)$;

lcd.print("ARUbot"); //Illk satıra yaza

lcd.setCursor $(0,1)$;

lcd.print("Ardahan Uni.");//İkinci satıra yazar\}

void loop 0\{\}

\section{7) LDR Kullanımına İlişkin Örnek Kodlar}

\#define ldrPin A4

void setup() \{ Serial.begin(9600);

void loop 0 \{Serial.println (analogRead(ldrPin)); delay(500); \}

\section{8) RGB Led Kullanımına İlișkin Örnek Kodlar} int renkler[] $=\{9,10,11\}$;

int sayac $=0$;

void setup 0

\{

pinMode(9,OUTPUT); // mavi

pinMode(10,OUTPUT); // yeșil

pinMode(11,OUTPUT); // kırmızı

digitalWrite(9,HIGH); //söndürmek için
digitalWrite(10,HIGH); //söndürmek için digitalWrite(11,HIGH); //söndürmek için \} void loop() \{

digitalWrite(renkler[sayac],LOW);//yakmak için

delay(1000);

digitalWrite(renkler[sayac],HIGH);//sndrmk için

sayac++

if $($ sayac $==3)\{$ sayac $=0 ;\}\}$

9) Servo Motor Kullanımına İlișkin Örnek Kodlar \#include < Servo.h> /* Servo kütüphanesi */

Servo servoNesnesi; /* servo motor nesnesi */ void setup 0\{

servoNesnesi.attach(3);

//servoNesnesi.write(90);

// Test için 90 derece döndürülebilir

void loop(0)

int aci baslangic $=50$

int aci_bitis=120;

for(int aci=aci_baslangic;aci<aci_bitis;aci++)\{

servoNesnesi.write(aci);

/* Motorun mili x dereceye donuyor *

delay(15); \}

for(int aci=aci_bitis;aci>aci_baslangic;aci--) \{

servoNesnesi.write(aci)

$/ *$ Motorun mili x dereceye donuyor */

delay(15); \} \}

10) TCRT5000 ile Çizgi İzlemeye İlişkin Örnek Kodlar

\#define cizgiPin1 A0

\#define cizgiPin2 A1

void setup0 \{ Serial.begin(9600);

void loop() \{

Serial.print(analogRead(cizgiPin1));

Serial.print(" ");

Serial.println(analogRead(cizgiPin2));

delay(500); $\}$

11) Ultrasonic Mesafe Sensoru Kullanımına İlişsin Örnek Kodlar

long sure,uzaklik

int trigPin $=12$;

int echoPin $=13$;

\#define buzzerPin A2

void setup 0\{

pinMode(trigPin,OUTPUT); //trig

pinMode(echoPin,INPUT); //echo

pinMode(buzzerPin,OUTPUT); //buzzer

Serial.begin(9600); $\}$

void loop() \{

digitalWrite(trigPin,LOW);

delayMicroseconds(2);

digitalWrite(trigPin,HIGH);

delayMicroseconds(10);

sure=pulseIn(echoPin,HIGH)

uzaklik=sure $/ 58$;

delay(50);

Serial.println(uzaklik);

if(uzaklik $>2$ and uzaklik<200)\{

tone(buzzerPin,440);

delay(uzaklik*10);

noTone(buzzerPin);

delay(100); \}\} 


\section{EXTENDED SUMMARY}

\section{INTRODUCTION}

If the literature on robotic coding education is searched, it is seen that many international studies (Rathy, Balaji and Nadu, 2018; Martn-Ramos et al., 2018; McCullen and Walters, 2018) use Arduino-based training sets. Arduino offers developers many opportunities thanks to its open source (Kasalak, 2017). Robotic coding requires both electronic circuit information and programming knowledge. At this point, there are researches that the situations that come up as obstacles in robot programming education (the difficulty of teaching abstract concepts to students and the lack of programming to address the interests of young people etc.) can be overcome by Scratch software prepared by MIT Lifelong Preschool Group. 2016). In the document review study conducted by Çatlak, Tekdal and Baz (2015) with 32 articles, it was found that Scratch software was effective in programming teaching, made programming more enjoyable and understandable, and also increased interest and motivation in programming education. Therefore, it can be said that nowadays, institutions can make their own training robots with open source circuit boards and software such as Arduino and Scratch, and that robots can be taught effectively with these robots.

In this study; for robotic coding education, it has been developed within Ardahan University. It is aimed to present a training robot that can work in harmony with the applications. In accordance with this purpose; How to develop a robotic training set (ARUbot) that can easily work on students, see the connection of circuit boards and modules, is very easy to carry and procure, is much lower cost than its peers from abroad, provides robotic coding instruction and can reduce the outflow of public resources.

\section{METHOD}

Within the scope of this research, waterfall model, which is one of the System / Software Project Management Models, was taken as a basis during the development of the material (ARUbot). The details of the 7-step development process of the Waterfall Model are presented below under the relevant headings.

\section{System requirements}

At this stage of the development process, a circuit board and the modules that will work in harmony with this circuit board were determined to develop the robotic training set. At this point, it was decided to use Arduino circuit board and modules because it is open source and can be provided with an appropriate budget (Kasalak, 2017).

\section{Software requirements}

At this stage, it is planned to use the Arduino IDE software, which can be downloaded free of charge from Arduino's own website (www.arduino.cc) at the software point needed for programming.

\section{Analysis}

In the analysis phase of the study;

- Robots used in STEM slope and their properties are examined,

- STEM related features in robots were examined,

- Advantages, advantages, limitations, difficulties and deficiencies of robots have been examined,

- The sensors and modules in the prototype to be developed are determined,

- A three-dimensional body is drawn to accommodate the sensors and modules.

\section{Design}

In the design stage of the study, it is emphasized how a circuit design can be done in which Arduino circuit board and modules can work in harmony with each other. At this point, first of all, all components are made working on a large breadboard.

\section{Coding}

The coding in Arduino can be done with the Arduino IDE, which can be downloaded free of charge from the Arduino website. Also, Scratch and so on. The codes of the applications prepared with block based visual 
programming tools can also be transferred. Therefore, users are given the freedom to choose a platform at the coding point.

\section{Testing and integration}

The prototype was first subjected to a physical test by the researchers. Upon understanding that all modular work continued in a healthy way despite small impacts, it was shown to faculty members at the Faculty of Engineering and their opinions were taken. As a result of the positive feedback received, it was concluded that the test process was completed successfully. Finally, ARUbot was introduced to the candidate students at the Ardahan University Promotion Days. After the positive feedback, this phase was completed.

\section{Maintenance and Care}

The development process of ARUbot will continue with the valuable contributions of students and faculty members of Computer Programming Department within the Department of Computer Engineering within the Faculty of Engineering and Ardahan Vocational School of Technical Sciences. For the present design, a more dramatic transformation can be achieved by the hand of a visualizer. There is no need for maintenance / repair for this prototype yet, but there may be failures due to modules / solders due to poor / hard usage in the future. In such cases, ARUbot is designed to be easily intervened by lifting the top cover.

\section{FINDINGS}

The findings obtained as a result of the development study are presented below under the headings of design, cost and possible applications.

\section{Findings on Design}

For the purpose of the study, a concrete prototype has been put forward about how a robot can be used in electronic and robotic coding training with the targeted features. When designing this prototype; which electronic circuit board and modules can be used, how the chassis can be seen and how the wheels can be. In consideration of all these points, a design has been put into which Ardunio circuit board and 11 modules can be operated.

\section{Findings on Cost}

In order to calculate the cost of the robot developed within the scope of the study, the cost of all components used was included in the calculation. ARUbot's Ardahan University electronic and robotic coding training robot seems to cost about 175TL ( \$29.7). Considering the fact that ARUbot has 11 modules on it and its pallet design, it is seen that it is 8 times more suitable than its foreign counterparts.

\section{Findings on ARUbot Applications}

The 11 modules on the ARUbot can be used individually or in combination. Thus, 2047 different usage and application can be achieved with combinations of 11 modules.

\section{DISCUSSION AND CONCLUSION}

In this study; ARUbot robot has been produced and it has been investigated how an easily programmable robotic training set can be used in electronic and robotic coding training. With 11 modules on ARUbot, 2047 different applications can be developed for users. Therefore, students are presented with a robot that they can perform experiments and applications with their own imagination. Moreover, the cost of this robot was only about 175TL ( $\sim 29.7)$. This finding is supported by the fact that Yang et al. (2019) emphasized the low cost of Arduino. The development of such a robot by the corporation has resulted in a cost advantage of approximately 8 times the purchase from its foreign counterparts. In addition, public resources flowing abroad in the purchase of robotic training sets can be significantly reduced. From this point of view, it can be said that a product guiding the STEM education in our country has been put forward. When evaluating the cost dimension of the product, it should not be ignored that many devices from the 3D printer to the soldering iron have been purchased for initial production, but not included in the calculated cost. 